\title{
JUSTIÇA E CONSENSO: PROTAGONISMO E CIDADANIA NA PERSPECTIVA CULTURAL DO DIÁLOGO
}

\author{
JUSTICE AND CONSENSUS: PROTAGONISM AND CITIZENSHIP FROM A CULTURAL \\ PERSPECTIVE OF DIALOGUE
}

\begin{abstract}
JUSTICIA Y CONCENSO: PROTAGONISMO Y CIUDADANÍA EN LA PRESPECTIVA CULTURAL DEL DIÁLOGO
\end{abstract}

Licença CC BY:

Artigo distribuído sob os termos Creative Commons, permite uso e distribuição irrestrita em qualquer meio desde que 0 autor credite a fonte original.

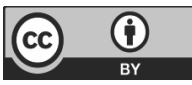

\section{Karinne Emanoela Goettems dos Santos ${ }^{1}$}

Resumo: O presente artigo é fruto de um constante questionamento acerca da concretização do acesso à justiça por meio do consenso. Para além das teorias de premissa maior e premissa menor e da separação entre fato de direito, este trabalho propõe uma reflexão sobre acesso à justiça e à cidadania, sobre jurisdição e sociedade, sobre rituais adversariais e consensuais. Para tanto, busca ilustrar o cenário da litigiosidade e, a partir dela, justificar a importância de rituais que, com base no consenso, valorizam a comunicação entre os conflitantes, transformando as relações sociais. Além disso, o estudo avança para a análise do consenso proposto pelo novo Código de Processo Civil e Lei de Mediação, destacando a participação e o protagonismo do cidadão neste processo de superação dos meios adversariais como fator de distinção para o exercício efetivo do acesso à justiça, defendendo sobretudo a riqueza do diálogo como ferramenta de emancipação e cidadania.

Palavras-chave: acesso à justiça; consenso; protagonismo; cidadania.

\begin{abstract}
This article is the result of a constant questioning about the achievement of access to justice through consensus. In addition to the theories of major premise and minor premise, and the separation of fact from law, this work proposes a reflection on access to justice and citizenship, on jurisdiction and society, over adversarial and consensual rituals. For this, it seeks to illustrate the litigiousness scenario and, from there, to justify the importance of rituals that, based on consensus, value communication between the conflicting parties and transform social relations. The study also examines the consensus proposed by the new Civil Procedure Code and Mediation Law, highlighting the participation and protagonism of the citizen in this process of overcoming adversarial situation, as a distinguishing factor for the effective exercise of access to justice, defending, above all, the richness of dialogue as a tool for emancipation and citizenship.
\end{abstract}

1 Doutora em Direito pela UNISINOS/RS. Professora Adjunta da Universidade Federal de Pelotas/RS, Brasil. E-mail: karinne.emanoela@ufpel.edu.br. 
Keywords: access to justice; consensus; protagonism; citizenship.

Resumen: El presente artículo es fruto de un constante cuestionamiento acerca de la concretización del acceso a la justicia por medio del consenso. Además de las teorías de premisa mayor y premisa menor y de la separación entre el hecho del derecho, este trabajo propone una reflexión sobre el acceso a la justicia y a la ciudadanía, sobre jurisdicción y sociedad, sobre rituales adversariales y consensuales. Para tanto, se busca ilustrar el escenario de la litigiosidad y, a partir de ella, justificar la importancia de rituales que, con base en el consenso, valoran la comunicación entre los conflictivos, transformando las relaciones sociales. Además, el estudio avanza para el análisis del consenso propuesto por el nuevo Código de Proceso Civil y Ley de Mediación, destacando la participación y el protagonismo del ciudadano en este proceso de superación de los medios adversariales como factor de distinción para el ejercicio efectivo del acceso a la justicia, defendiendo sobre todo la riqueza del diálogo como herramienta de emancipación y ciudadanía.

Palabras clave: acceso a la justicia; consenso; protagonismo; ciudadanía.

\section{INTRODUÇÃO}

Já no final do século XX observa-se um intenso movimento de judicialização da vida social e política, cujas bases, segundo Boaventura de Sousa Santos, estão assentadas no novo modelo de desenvolvimento em prol do mercado e na precarização dos direitos econômicos e sociais. ${ }^{2}$ O Judiciário, assim, tem sido o reduto de um clamor social diante da fragilidade das instituições democráticas. ${ }^{3}$ Ao mesmo tempo, assiste-se a uma divinização da magistratura ao nível do sacerdócio, ${ }^{4}$ imagem simbólica esta que legitima os julgadores como agentes detentores da verdade. ${ }^{5}$

Nesse cenário, preponderaram os rituais adversariais de solução de conflitos, na mesma intensidade com que seus standards imperam na pedagogia do ensino jurídico no Brasil. ${ }^{6}$ Essa polarização simbólica da ritualística processual está bem internalizada na cultura jurídica brasileira.

E a ruptura epistemológica que se faz necessária sobre essa lógica implica o que Pierre Bourdieu compreende como conversão do pensamento, como a revolução do olhar e de uma mudança de visão sobre o mundo social, a partir do

2 SANTOS, Boaventura de Sousa. Para uma revolução democrática da justiça. 3. ed. São Paulo: Cortez, 2011 , p.24.

3 GARAPON, Antoine. O guardador de promessas: justiça e democracia. Tradução de Francisco Aragão. Lisboa: Instituto Piaget, 1996, p.23.

4 MAUS, Ingeborg. O Judiciário como superego da sociedade: o papel da atividade jurisprudencial na "sociedade órfã". Novos Estudos CEBRAP, São Paulo, n. 58, p.196, nov. 2000. Disponível em: http://www.direitocontemporaneo.com/wpcontent/uploads/2014/02/JUDICI\%C3 \% 81RIO-COMO-SUPEREGO-DA-SOCIEDADE.pdf. Acesso em: 01 jun. 2017.

5 FOUCAULT, Michel. Microfísica do poder. 26. ed. Tradução de Roberto Machado. Rio de Janeiro: Graal, 1979, p.14.

6 SANTOS, Boaventura de Sousa. Para uma revolução democrática da justiça, p.87. 


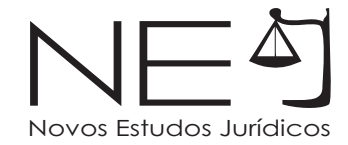

"por-em-suspenso as pré-construções vulgares e os princípios geralmente aplicados na realização dessas construções". É o que o presente estudo se propõe a fazer.

O novo Código de Processo Civil (Lei 13.105/2015), de certa forma, consegue dar início a uma nova compreensão sobre os rituais de solução de conflitos ao estimular a via do consenso. Já no primeiro capítulo, destinado às normas fundamentais do processo civil, o código situa diretrizes que devem guiar a aplicação na prática da nova lei processual, dentre as quais se destaca o art. $3^{\circ}$, nos parágrafos $2^{\circ}$ e $\$ 3^{\circ}$, que impõem à magistratura, ao ministério público e à advocacia pública e privada um dever de estímulo à solução consensual de conflitos, a exemplo da mediação e da conciliação, redirecionando, assim, a atenção do acesso à justiça para o universo do diálogo.

O ambiente jurisdicional, a partir dessa nova concepção, não está mais restrito a métodos exclusivamente adversariais de solução de conflitos. Aos sujeitos processuais estão disponíveis outras técnicas, em caráter extra ou endo processual, técnicas estas chamadas de alternativas e que agora passam também a integrar o sistema de prestação jurisdicional.

Segundo Oscar Chase, é possível conhecer uma cultura pelas práticas de solução de conflitos adotadas por determinado país, bem como pelo grau de compromisso assumido para com tais práticas. $^{8}$ Neste sentido, ainda que o Estado, por meio dessa perspectiva consensual, tenha o interesse de despir-se de sua autoridade para aliviar o quantitativo excessivo de processos, o primado dessa mudança de perspectiva está calcado seriamente em políticas públicas de acesso à justiça, a fim de viabilizar o pleno exercício da cidadania.

Contudo, há também o desafio de introduzir ou internalizar essa proposta do meio consensual, calcado no diálogo e na solidariedade, que vem na contramão de uma sociedade complexa e sobretudo individualista.

Sendo assim, para o cidadão, o que de fato tal mudança de perspectiva significa? Qual é o cenário que essa nova racionalidade deve encontrar? A cultura brasileira expressa valores de abertura, solidariedade e cooperação, necessários

7 BOURDIEU, Pierre. O poder simbólico. Tradução de Fernando Tomaz. Rio de Janeiro: Bertrand Brasil, 2006. p. 49.

8 CHASE, Oscar G. Direito Cultura e Ritual: Sistemas de Resolução de conflitos no contexto da cultura comparada.

1. ed. Tradução de Sérgio Arenhart, Gustavo Osna. São Paulo: 2014, p.34. 
para a recepção da justiça consensual ou será o rito consensual que deverá construir e transformar o cenário cultural compatível com a sua aplicabilidade?

Essa investigação precisa ser conduzida, portanto, tanto sob as lentes dos rituais de solução de conflito, notadamente no que se refere à adequação entre rito e conflito, como também a partir do comportamento dos sujeitos processuais envolvidos neste mesmo ritual.

De tal forma, este estudo é fruto de um constante questionamento acerca da concretização do acesso à justiça por meio do consenso, em meio aos paradoxos da sociedade contemporânea. Sob este viés, como é possível incorporar neste perfil social uma justiça consensual sob a perspectiva diálogo? Por que é relevante analisar o extrato social quando se pretende debater as condições de acesso à justiça na contemporaneidade? Qual, de fato, é a importância de compreender o conflito social e sua natureza para avaliar a adequação do ritual utilizado para a sua estabilização?

A partir dessas diretrizes, para além das teorias de premissa maior e premissa menor e para além do princípio da substanciação, que separa fato de direito na teoria dos elementos da ação, este trabalho propõe uma reflexão sobre acesso à justiça e à cidadania, sobre jurisdição e sociedade, sobre rituais adversariais e consensuais. Para tanto, busca ilustrar o cenário da litigiosidade e, a partir dela, justificar a importância de rituais que, com base no consenso, valorizam a comunicação entre os conflitantes, a exemplo do que ocorre com o direito de família e o direito de vizinhança, estabelecendo compromissos e compreensão mútuos e provocando o que se pode chamar de transformação cultural das relações.

Inicialmente, o artigo abre com um olhar sobre a realidade brasileira a partir dos indicadores sociais e sobre o cenário do poder judiciário segundo o Conselho Nacional de Justiça, para, passo seguinte, avançar para a análise dos rituais de solução de conflitos oferecidos pelo ordenamento jurídico. Ao final, o texto apresenta as expectativas advindas com a edição do novo Código de Processo Civil, em março de 2015, bem como da Lei de Mediação, em junho do mesmo ano, que destacam a participação e o protagonismo do cidadão, neste processo de superação dos meios adversariais, como fator de distinção para o exercício efetivo do acesso à justiça. Nas considerações finais, o estudo pretende defender a riqueza do diálogo usado pelos meios consensuais e sua reflexividade com o meio social. 


\section{OS FATOS SOBRE A MESA: UM OLHAR HORIZONTAL SOBRE A REALIDADE SOCIAL}

Observar com honestidade o modelo de jurisdição requer necessariamente um olhar sobre os fatos de uma sociedade complexa, desigual e inserida em um ambiente globalizado sem precedentes. $O$ direito dos conceitos e afeito ao mundo dos códigos já teve seu momento. O século XXI exige bem mais do que isso. Para tanto, é preciso direcionar esse olhar para a realidade social, nesse locus das ruas, das famílias, do trabalho e da economia, com todas as suas contingências e circunstâncias de tempo e espaço.

Ovídio Baptista da Silva já comungava, especialmente em suas últimas obras, de justificável preocupação com uma jurisdição compatível com a realidade contemporânea, bem como sua angústia frente à "falta de compreensão adequada aos fatores culturais que nos aprisionam, fazendo com que andemos em círculos, sem que nenhum progresso efetivo se tenha obtido". ${ }^{9}$

Seguindo o mestre, esse olhar segue nessa direção em que é possível encontrar trabalhadores, consumidores ou qualquer cidadão membro de algum núcleo familiar que, na vida cotidiana, vai enfrentar contingências de exploração no ambiente de trabalho; vai experimentar desentendimentos da vizinhança distante e de lares abismais e vazios, nos quais os filhos são os mais afetados: ${ }_{1}^{10}$ vai frustrar-se, ainda, com fornecedores de bens e serviços que impõem contratos abusivos e danosos sobre suas rendas, vidas ou saúde, pois além de um dano ambiental suicida, consome-se uma produção de alimentos carregados de uma química nociva à saúde.

$\mathrm{Na}$ dura realidade do cotidiano, ainda, esse olhar vai encontrar muitos trabalhadores que executam os serviços menos desejosos, porém necessários na rotina urbana (até mesmo porque não ter emprego é uma situação ainda mais indesejada). No layout paradoxal das cidades, esse olhar facilmente encontra moradias precárias e em desacordo com aquilo que se pretende digno em nível de direitos humanos (assim como é comum encontrar pessoas cujo "domicílio" é a própria rua, com o agravante de, por vezes, estarem acompanhadas de crianças);

9 SILVA, Ovídio Baptista da. Processo e Ideologia - o paradigma racionalista. 2. ed. Rio de Janeiro: Forense, 2006, pagina X do Prefácio.

10 LIPOVETSKI, Gilles. A era do vazio: ensaios sobre o individualismo contemporâneo. Tradução de Therezinha Monteiro Deutsch. São Paulo: Manole, 2005. p.59-60. 
enquanto no outro extremo, de forma desconcertante, observa-se uma distinta parcela da sociedade que, com trabalho e rendimentos "dignos", consome bens e serviços destinados a poucos, o que inclui moradia adequada, lazer, educação e saúde, para a si e sua família, privilégios estes conhecidos como direitos sociais.

Por fim, esse olhar ainda encontra no dia a dia da vida contemporânea uma indesejada intolerância de toda ordem. Sim, em pleno regime democrático no século XXI, de intensa diversidade e pluralismo, não se vê a evolução da compreensão da diferença de gênero, de cor, de classe, entre outros.

Então é preciso falar de um esgotamento das instituições, do Estado, dos sistemas de justiça e de uma democracia que prometeu muito e criou muitas expectativas que hoje frustram o cidadão mais otimista. Há sobretudo um esgotamento de um modelo econômico-social que alimenta uma violência simbólica a partir de acordos culturais opressores, sobretudo em decorrência de uma absurda desigualdade que retroalimenta esse mesmo modelo. ${ }^{11}$ É a opressão do capital sobre a vida digna. E isso é uma amostra de um regime democrático, indefensável em termos constitucionais.

E é nisso que consiste o primeiro ponto: esse modelo não está lá, está aqui. Querendo ou não, se é parte disso e se é afetado por isso. De fato, se está verdadeiramente no "olho do furacão". E se o conflito é algo natural sob o ponto de vista sociológico, sua potência é infinitamente maior em um ambiente de diferenças.

E diante do conflito, o cidadão precisa contar ainda com o exercício do direito constitucional de acesso à justiça para restabelecer sua cidadania. Mais um longo passo, partindo do pressuposto de que outros direitos fundamentais não são experimentados na prática. Apenas para exemplificar, lazer é um direito fundamental no art. $6^{\circ}$ da Constituição. Para quem? Complexo demais, portanto.

O fato é que o olhar sobre essa realidade é indispensável para a compreensão da experiência do conflito e dos seus sujeitos, no tempo e no

11 Para o Relatório de Desenvolvimento Humano (RDH) 2016, publicado pelo Programa das Nações Unidas para o Desenvolvimento (PNUD), apenas $1 \%$ da população mundial concentra $46 \%$ da riqueza mundial. Levando em consideração o Índice de Desenvolvimento Humano (IDH), embora o Brasil esteja no grupo considerado com índice "alto", o país está em $79^{\circ}$ lugar no quadro geral, com IDH 0,754. Mas se considerada a variação do IDH com relação à desigualdade (IDHD), o Brasil perde 19 posições, registrando um IDHD de 0,561. Ver em PNUD, Relatório de Desenvolvimento Humano 2016, p.46. Disponível em: <http://hdr.undp.org/sites/default/files/ 2016_ human_development_report.pdf>. Acesso em: 22 mar. 2017. 
espaço, especialmente quando parcela significativa da população vive em uma dimensão aquém da dignidade e se encontra em uma posição um tanto "debilitada", que dificulta inclusive sua capacidade de reação e de superação das limitações sociais. Trata-se de uma massa de eleitores sem representação. Uma multidão sem oportunidades.

Também é preciso restar claro que tal discussão não pode conceder espaços para discursos falso-ideológicos que venham a deslizar sobre o debate raso e maniqueísta entre esquerda e direita. Está-se falando de pessoas. Estáse tratando, de forma honesta, da não materialização de uma cidadania e da dificuldade de exercer direitos fundamentais basilares, pautados em direitos humanos há anos sedimentados nas cartas universais de direitos.

Gadamer considera a "consciência histórica efeitual" como elemento integrante do processo de compreensão, na qual a facticidade encontra sua marca na compreensão da tradição histórica, ou seja, a estrutura universal da compreensão atinge sua concretude na compreensão histórica, uma vez que os vínculos concretos de costume e tradição e suas correspondentes possibilidades de futuro tornam-se operantes na própria compreensão. ${ }^{12}$ Enquanto o Direito mantiver uma posição hermética e anacrônica, e deixar de pressupor um mínimo de consciência histórica efeitual, mostra-se que é impossível compreender o conflito social em sua essência, tampouco será possível tratar deste conflito adequadamente, por meio de mecanismos processuais utilizados a partir da identidade do conflito.

Portanto, não há mais tempo para a clínica geral da jurisdição tradicional. É preciso superar a compreensão rasa de que há uma premissa maior a ser aplicada sobre uma premissa menor. Sem esse olhar horizontal sobre o conflito social, o modelo adversarial vai continuar com seu movimento circular sem qualquer contribuição para a sociedade. Tal qual adverte Boaventura, se o sistema judicial não assumir a sua quota-parte de responsabilidade, será cada vez mais irrelevante para a sociedade, tanto social como politicamente. ${ }^{13}$

12 GADAMER, Hans Georg. O problema da consciência histórica. Tradução de Paulo Cesar Duque Estrada. Rio de Janeiro: Fundação Getúlio Vargas, 2003, p.43.

13 SANTOS, Boaventura de Sousa. Para uma revolução democrática da justiça, p.40. 


\section{DO CARÁTER SUBSTITUTIVO DA JURISDIÇÃO AO CONSENSO: UM NECESSÁRIO RETORNO DO PROTAGONISMO DO CIDADÃO}

"São interpretações que legitimam decisões, roubando o tempo das partes: nos conflitos (transformados em litígios) submetidos à decisão dos tribunais de justiça, as partes perdem o direito de dispor do seu tempo". (Luis Alberto Warat, Em nome do acordo, p.33).

Chiovenda definia jurisdição como função do Estado que se realiza através de órgãos públicos em substituição à vontade das partes. ${ }^{14}$ Trata-se de conceito clássico de heterocomposição que revela a intervenção de uma autoridade que se substitui às partes conflitantes e sobre elas impõe sua decisão, seja por terem esgotado as medidas de resolução do conflito sem essa intervenção, seja porque o ordenamento jurídico impõe essa intervenção por interesse público.

Diante desse cenário, o que ora se pretende destacar é a atuação da jurisdição sob outro aspecto, qual seja o momento em que o cidadão, embora o ordenamento assim o permita, renuncia à opção do diálogo e ao consenso para o tratamento ou a transformação do conflito. ${ }^{15}$ Neste caso, quando o cidadão exerce o seu direito de ação e clama pela intervenção da jurisdição para a solução do conflito de interesses, decide substituição a sua participação pela imposição de um terceiro, renunciando, assim, ao seu protagonismo neste processo.

Da mesma forma, apesar de instaurado o processo, esse caminho também pode ocorrer quando o cidadão renuncia à oportunidade de realização de audiência de mediação ou de conciliação (art.334 do novo CPC) ou à possibilidade de alteração do rito processual (art.191 do novo CPC). A partir deste momento, o processo vai trilhar pelas veredas do contencioso e ganha as estatísticas da litigiosidade.

Segundo o Relatório Justiça em Números, publicado pelo Conselho Nacional de Justiça em outubro de 2016, são ao todo 101.216.596 milhões de processos registrados no Poder Judiciário para o ano de 2015. Deste contingente de quase 102 milhões de processos, a justiça estadual é responsável por conservar $77 \%$

14 CHIOVEDA, Giuseppe. Instituições de direito processual civil. Tradução Paolo Capitaneo. Campinas: Bookseller, 1998, Vol.2, p.8.

WARAT, Luis Alberto. Em nome do acordo. A mediação no direito. 2. ed. Buenos Aires: Almed, 1999, p.8. 


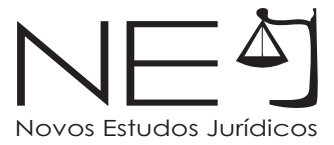

do acervo. Essa margem de percentual tem se mantido estável nos últimos anos, bem próxima à casa dos $80 \% .^{16}$

Na justiça estadual, são ao todo cerca de 78 milhões de processos, dos quais 59.030.179 são casos pendentes e 18.911.657 são casos novos. No aspecto qualitativo, a justiça estadual, de acordo com o mesmo Relatório, registra uma recorrência de demandas ingressantes no ano de 2015 (casos novos) voltadas para a área obrigacional, contratual, consumerista, de responsabilidade civil por dano moral e conflitos de família, ${ }^{17}$ repetindo, praticamente, a categoria de demandas registradas no Relatório anterior, referente ao exercício de 2014. Neste ranking, afora as questões tributárias que aparecem em $3^{\circ}$ lugar, os seis primeiros lugares estão ocupados pelas questões cíveis antes mencionadas. Está-se no campo do crédito, da inadimplência ou do superendividamento, da renda insuficiente, da precarização das relações. Qualquer relação entre a recorrência destas temáticas e a desconcertante desigualdade social não é mera coincidência.

Por outro lado, o Relatório Justiça em Números também tem divulgado sua avaliação sobre a produtividade do Judiciário, utilizando o indicador "carga de trabalho" que considera o número de procedimentos pendentes ou resolvidos por magistrados e servidores. É importante observar as duas maiores justiças de primeiro grau que concentram o maior número de juízes ( $86 \%$ do total de magistrados do Judiciário). ${ }^{18}$ Conforme referido anteriormente, a justiça estadual cadastra $77 \%$ dos processos, seguida da justiça federal com $12,58 \%$. Inversamente ao número total de processos, o número de casos novos por magistrado no primeiro grau é maior na justiça federal (1.823 para 1.590$),{ }^{19}$ sendo mínima a diferença da carga de trabalho entre as referidas justiças neste grau de jurisdição: 7.432 na federal e 8.219 na estadual. ${ }^{20}$

Em termos de produtividade dos magistrados de primeiro grau, a justiça federal tem o maior índice - 1.979 -, seguida da justiça estadual com o índice de 1.895 de produtividade, o que é uma desproporção significativa diante do acervo

16 SANTOS, Karinne Emanoela Goettems dos. Processo Civil e Litigiosidade - Para além da jurisdição dos conceitos sem coisas. Rio de Janeiro: Lumen Juris, 2016, p.49.

17 BRASIL, Conselho Nacional de Justiça. Relatório Justiça em Números 2016, Volume1, p.141. Disponível em: http:// www.cnj.jus.br/files/conteudo/arquivo/2016/10/b8f46be3dbbff344931 a933579915488.pdf. Acesso em: fev. 2017.

18 Relatório Justiça em Números 2016, Volume 1, p.37.

19 Relatório Justiça em Números 2016, Volume 1, p.53.

20 Relatório Justiça em Números 2016, Volume 1, p.54. 
que a justiça estadual concentra ( $77 \%$ do total de processos do Judiciário). ${ }^{21}$

Já a taxa de congestionamento, outro dado a ser avaliado na questão da produtividade, sempre beirou a casa dos $80 \% .^{22}$ A diferença para o ano de 2015 , quando ela cai para $75 \%$ na estadual e $72 \%$ na federal, decorre da alteração da fórmula de cálculo que, a partir do exercício de 2015, passou a desconsiderar os dados relativos aos processos suspensos, sobrestados e em arquivo provisório, 23 de modo que a sensível queda de congestionamento, em comparação ao exercício de 2014, não pode ser motivo de comemoração.

Os números parecem insípidos e inodoros, mas permitem deduzir, num primeiro momento, que a crescente litigiosidade não decorre simplesmente da abertura democrática na década de 80 ou da elevação do direito de ação como direito constitucional fundamental, pois a explosão do número de processos é um fenômeno social e não jurídico. ${ }^{24}$ Ou seja, o deslocamento do poder de regulação do Estado para a economia gera o enfraquecimento da democracia, afetando de forma significativa a cidadania. Se o Estado, com sua crise multifacetada, está infectado pela invasão do poder econômico, o Judiciário, legitimado pela simbologia paternalista, acaba por se tornar efetivamente o reduto do âmago social experimentado pelo cidadão infantilizado. ${ }^{25} \mathrm{~A}$ judicialização da vida é a evidência do enfraquecimento da cidadania.

Segundo, é irrelevante o número de juízes quando se fala de efetividade jurisdicional. Medir a produtividade também parece mais um coeficiente sofisticado para abrilhantar as estatísticas e brindar o poder econômico com a necessária eficácia que o um sistema judicial que se preze deve manter. ${ }^{26}$ Por outro lado, por mais dedicados que magistrados e servidores possam parecer ser em busca da tramitação ideal dos processos, a julgar pela manutenção da taxa de congestionamento em torno de $80 \%$, para o cidadão nada mudou nos últimos dez anos. A esse respeito, veja-se a diferença de quadro entre a justiça estadual e a justiça federal e a desproporção entre número de processos e de juízes.

21 Relatório Justiça em Números 2016, p.55.

22 SANTOS, Karinne Emanoela Goettems dos. Processo Civil e Litigiosidade, p.54-55.

23 Relatório Justiça em Números 2016, p.48 e 49.

24 GARAPON, Antoine. O guardador de promessas: justiça e democracia, p. 22.

25 BOLZAN DE MORAIS, José Luis. O Estado e seus limites. Reflexões iniciais sobre a profanação do Estado Social e a dessacralização da modernidade. Boletim da Faculdade de Direito n. 83, 2007. p.576-577.

SANTOS, Boaventura de Sousa. Para uma revolução democrática da justiça, p.24. 
Por outro lado, com o fetiche da produtividade, o Judiciário talvez consiga demonstrar seu patamar de eficácia em termos quantitativos no ambiente da gestão pública, o que não se confunde com o atendimento dos fins sociais, das exigências do bem comum e da dignidade do cidadão, especialmente considerando o escopo constitucional da efetividade da prestação jurisdicional, conceito este tão caro quando se coloca como condição de acesso à justiça.

O fato é que a efetividade da prestação jurisdicional está além das estatísticas, pois o acesso à justiça, na altura dos direitos fundamentais, não se apresenta no ranking dos tribunais, mas no dia a dia do cidadão frente ao conflito tratado e estabilizado.

As estatísticas, portanto, devem ser sobretudo um estímulo para que o cidadão retome seu protagonismo no processo de solução dos conflitos, dentro da esfera de disponibilidade de seus direitos. No momento em que o cidadão reassume a sua capacidade de diálogo com o outro, esse ninguém que passa a ser alguém do outro lado da mesa redonda, que por sua vez também se autonomiza neste processo de retomada da comunicação.

Tal perspectiva não pode ser compreendida como um desprestígio da jurisdição. O que se pretende de fato é relegar para a jurisdição apenas os conflitos de interesses cuja solução não possa ocorrer pela via do consenso, cujo diálogo não tenha capacidade de tratar e solucionar o problema. Para o ambiente precioso, caro e complexo que é a jurisdição, relegue-se então apenas as demandas igualmente complexas.

Mas essa perspectiva é sabidamente audaciosa, sobretudo porque depende de uma série de fatores conjugados para o cumprimento de seu desiderato. ${ }^{27} \mathrm{De}$ momento, para essa nova racionalidade de consenso, resta saber se os sujeitos processuais estão comprometidos e preparados para o papel que lhes cabe. É o que se pretende debater a seguir.

\section{O NOVO CPC E O ESPAÇO PARA O PROTAGONISMO E AUTODETERMINAÇÃO DAS PARTES}

"O diálogo é "ato político real entre as diferenças que evoluem na busca do conhecimento e da ação que dele deriva". (Márcia Tiburi, Como conversar com um fascista, p. 47).

27 SANTOS, Boaventura de Sousa. Para uma revolução democrática da justiça, p.39. 
O direito de ação compreende não apenas o direito à tutela jurisdicional adequada, mas também a um processo adequado ao direito substancial ${ }^{28}$ e, portanto, adequado ao conflito. A propósito, Cappelletti já reconhecia outrora "a necessidade de correlacionar e adaptar o processo civil ao tipo de litígio".29

O novo Código de Processo Civil (Lei n. 13.105/2015) assume de fato esse escopo constitucional de efetividade e qualifica o acesso à justiça ao trazer, entre outras inovações, dois importantes valores: primeiro, a promoção do consenso, a partir da reconfiguração do rito comum e nele colocando a audiência de mediação e de conciliação (art.334) como ato processual distinto para uma nova oportunidade de retomada do protagonismo das partes (art. $3^{\circ}$ ); segundo, a abertura para a autodeterminação a partir do incentivo da arbitragem (art. $3^{\circ}$, $\S 1^{\circ}$ ) e da flexibilização do procedimento de acordo com o interesse das partes, o que designa de negociação processual (art.190).

Essa proposta provoca uma avaliação acerca da própria efetividade da prestação jurisdicional, no patamar constitucional, como expressão de soberania do Estado, especialmente a partir da eficácia dos direitos fundamentais. ${ }^{30}$

Inicialmente, com relação à promoção do consenso, o novo CPC institucional, o chamado modelo multiportas de resolução de conflitos, de origem norteamericana, a partir do trabalho de Frank Sander. ${ }^{31}$ Para esta nova lógica, no trâmite processual, o juiz deverá promover, a qualquer tempo, a autocomposição, preferencialmente com auxílio de conciliadores e mediadores judiciais (art,139, V (PC), cuja função está bem disciplinada a partir do art.165 do referido diploma legal. Segundo o código, os mediadores atuarão preferencialmente nos casos em há vínculo entre as partes e preferencialmente os conciliadores no caso deste vínculo inexistir. ${ }^{32}$

28 MEDINA, José Miguel Garcia. Direito Processual Civil Moderno. São Paulo: Revista dos Tribunais, 2016, p.138.

29 CAPPELLETTI, Mauro; GARTH, Bryant. Acesso à Justiça. Tradução de Ellen Gracie Northfleet. Porto Alegre: Fabris, 1988, p.71.

30 MARINONI, Luiz Guilherme. Teoria Geral do Processo. 7. ed. São Paulo: Revista dos Tribunais, 2013, p.84.

31 ALMEIDA, Rafael Alves de; ALMEIDA, Tania; CRESPO, Maria Hernandez (Org.). O Tribunal Multiportas Investindo no capital social para maximizar o sistema de solução de conflitos no Brasil. Rio de Janeiro, Editora FGV, 2012, p.25. Disponível em: http://bibliotecadigital.fgv.br/ dspace/bitstream/handle/10438/10361/Tribunal\%20 Multiportas.pdf?sequence=1. Acesso em: 20 mar. 2017.

32 Não obstante essa abertura para novos modelos, não é unânime na doutrina a previsão de que a mediação seja realizada também no âmbito judicial. Neste sentido, Petrônio Calmon defende que a mediação é um instituto de autocomposição exclusivamente privado e que a própria Lei de Mediação parece confundir os conceitos de mediação e de conciliação. Aliás, o autor discorda até mesmo da necessidade de uma lei que disciplina o instituto, dada a sua natureza privada. Ver em CALMON, Petrônio. Fundamentos da mediação e da conciliação. 3. ed. Brasília: Gazeta Jurídica, 2015, p.103. 
No rito comum, a oportunidade de consenso pode renovar as expectativas de uma solução dialógica, por meio da qual as partes, por autodeterminação, retomam o protagonismo da solução, sem a intervenção de um terceiro alheio ao conflito. Em conflitos de vizinhança, por exemplo, nos quais as desavenças brotam da convivência diária, a restauração do diálogo é essencial como solução e até mesmo como prevenção de novos conflitos, dado o seu intenso caráter relacional decorrente da convivência ser permanente, em que os conflitantes convivem antes, durante e depois do processo.

Conforme se depreende do parágrafo $4^{\circ}$ do art.334, para que a nova audiência de tentativa de conciliação ou de mediação seja designada, basta que uma única parte se manifeste a favor da sua realização. Isso revela a importância que o procedimento está depositando no desfecho do conflito por meio da autonomia das próprias partes e sem a tramitação regular do processo até a decisão final. 0 ritual revela, sobretudo, a oportunidade dada às partes para que assumam o seu protagonismo na solução do litígio, fortalecendo sua capacidade de autonomia e transformando o conflito em algo positivo para as relações que porventura venham a se perpetrar ao término do processo.

Esses resultados só podem ser obtidos por meio do diálogo, que pode alcançar o consenso como justiça das partes. Essa lógica de autocomposição é facilmente contrastada com a heterocomposição, por meio da qual a decisão de uma única autoridade, alheia ao conflito, impõe sua decisão que fatalmente tornará uma das partes sucumbente. No consenso notadamente não há sucumbência.

E a nova sistemática leva a sério a importância da audiência. Em razão dessas expectativas depositadas sobre o ato, a ausência das partes sem a devida justificativa passa a ser considerada ato atentatório à dignidade da justiça, implicando, inclusive, a cominação de multa de até $2 \%$ sobre a vantagem econômica pretendida ou do valor da causa, valor este que será revertido em favor da União ou do Estado (art.334, §8º).

O autor deve ser o primeiro a se manifestar acerca da audiência, eis que o desejo ou não pela sua realização constitui-se em requisito da petição inicial (art.319, inciso VII). O réu, por sua vez, caso silencie em até 10 dias antes da audiência designada, demonstra sua concordância tácita pela audiência (art.334, §, 5º). 
Cabe destacar também que é o próprio conceito de citação que reforça a compreensão desse incentivo à realização da audiência, já que, para o art. 238 do novo Código, ao ser citado, o réu é convocado para "integrar a relação jurídica processual", e não diretamente para contestar a ação. Trata-se de uma linguagem renovada que tem uma relevância significativa quando se trata de promover o consenso em detrimento de práticas adversariais.

Essa proposta também é acompanhada da Lei de Mediação (Lei 13.1402015), que detalha os procedimentos de mediação entre particulares, na via extrajudicial, legitimando, ainda, sua prática entre cidadãos e Administração Pública. Trata-se de regramento que vem esclarecer e garantir sobretudo a eficácia do procedimento de mediação na via extrajudicial, que resulta em título executivo extrajudicial em caso de acordo (art.784 do novo (PC), apenas necessitando da homologação judicial em caso de conflitos envolvendo direitos indisponíveis (art. 515, III do novo CPC e art. $3^{\circ}$ e seus parágrafos e art.20, parágrafo único, da Lei 13.140/2015).

Cabe ainda uma última referência ao novo rito especial previsto para as ações de família, no capítulo aberto pelo art.693 do novo CPC, pressupondo a existência de litígio para processos de divórcio, separação, reconhecimento e extinção da união estável, guarda, visitação e filiação. Primeiro, o ritual especial resguarda tratamento adequado à família, então considerada como instituto basilar da sociedade, conforme previsão do art.226 da Constituição Federal, bem lembrada por Nelson Nery Jr. ${ }^{33}$ Segundo, a introdução de rito especial para demandas de família é acertada no novo CPC, atendendo ao critério de que conflitos especiais merecem tratamento e ritual diferenciados e adequados à sua natureza.

Nesse sentido, o novo rito especial de família respeita as complexidades das relações humanas, vindo ao encontro da concepção lacaniana de que o indivíduo se comporta de acordo com sua realidade psíquica, construída em um ambiente familiar, como núcleo social primeiro, capaz de amoldar, constituir e transmitir culturalmente, passando a ser absorvido pelo indivíduo. ${ }^{34}$ Nesta perspectiva, o procedimento da mediação, quando busca restabelecer o diálogo por profissional habilitado para a complexidade do conflito, acaba por respeitar

33 NERY JR., Nelson. Comentários ao Código de Processo Civil. São Paulo: RT, 2016, p.1625.

34 LACAN, Jacques. Os complexos familiares na formação do indivíduo. Tradução de Marco Antônio Coutinho Jorge e Potiguara Mendes da Silveira Júnior. Rio de Janeiro: Jorge Zahar, 2002, p.12-13. 


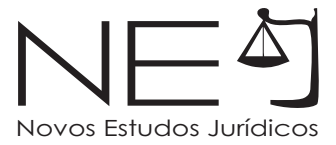

as especificidades do conflito e sua natureza, aproximando-se das técnicas da psicanálise ao desvelar o que resta mascarado pelo inconsciente.

O que o novo rito apresenta, de fato, de especial, diferentemente da audiência do art.334 do rito comum, é a obrigatoriedade da realização de audiência de mediação e conciliação, prevista no art.695, pois a toda evidência, em se tratando da natureza complexa do conflito familiar, é até mesmo questionável a eficácia de uma decisão judicial para a resolução do conflito, na medida que, nas decisões judiciais, a satisfação de uma das partes implica necessariamente a insatisfação da outra ${ }^{35}$ e, em se tratando de relações de afeto, a sucumbência é sempre prejudicial para uma relação que, embora transformada legalmente, irá continuar existindo de alguma maneira no pós processo.

Diante disso, não há dúvidas de que o rito previsto no capítulo $\mathrm{X}$ dos Procedimentos Especiais (título III do Livro I da Parte Especial) do novo CPC revela política pública de atendimento a uma demanda social muito comum, constituindose em procedimento constitucionalmente adequado à natureza do conflito.

Contudo, afora o êxito que pode advir do trabalho realizado por mediadores por meio dos Centros Judiciários de Solução de Conflitos (CEJUSCS), é possível arriscar no argumento de que o Judiciário não é o locus adequado para o tratamento de conflitos dessa ordem, seja pela excentricidade de sua natureza, seja pela dinâmica do tempo dos afetos. Nos corredores das varas de família, fica a impressão de que o processo fica deslocado do conflito. O procedimento judicial não está sintonizado com a essência da desavença. A cada audiência ou a cada sentença, resta a conclusão de que ali não era o lugar do problema, pois fica algo a se resolver. O processo se resolve, mas não o conflito. Todo o sistema padece, portanto.

Por outro lado, é preciso registrar que o referido procedimento especial acabou prevendo menos do que poderia prever, pois são poucas as "especialidades" do rito e suas diferenças frente ao rito comum, a exemplo da estrutura do mandado de citação, desacompanhado da contrafé e da obrigatoriedade da audiência de mediação e conciliação. Caso não haja acordo, a apresentação de defesa por parte do réu "converte" o rito especial e rito comum a partir no art.335 do novo CPC. Da mesma forma, poderia o novo CPC ter absorvido o rito relativo às ações de alimentos. Contudo, restou mantida a legislação extravagante relativa à matéria (Lei 5.478/1968).

35 WARAT, Luis Alberto. Em nome acordo, p.16. 
De qualquer forma, mostra-se relevante a obrigatoriedade da audiência de mediação e conciliação, uma vez que se instaura a oportunidade de diálogo, como instrumento indispensável de retomada da comunicação entre os litigantes a fim de restaura as relações e, dentro do possível, alcançar o consenso.

Até o momento, sem a intervenção do novo rito comum, eis que a última apuração do CNJ considera o exercício de 2015, a justiça estadual registra um módico índice de conciliação de 10,7\% e a justiça federal de 4\%. ${ }^{36}$ Fica também a expectativa de que a gradativa implantação dos CEJUSCs (Centros Judiciários de Solução de Conflitos e Cidadania), impulsionados pela Resolução 125/2010 do CNJ e agora incorporados a partir do art.165 do novo CPC venham a ampliar os números do consenso e façam frente à proporção de processos decididos pelo meio adversarial.

Já o negócio processual previsto no art.190 do novo CPC, por sua vez, também enseja a necessária e prévia harmonização das partes a fim de que a modificação do procedimento possa ocorrer. Ou seja, a negociação pelo ritual também requer consenso prévio.

Tal convenção, que pode inclusive ocorrer na fase pré-processual, admite como objeto a ser flexionado o procedimento, ônus, poderes, faculdades e deveres das partes. Tal poder de intervenção sobre o procedimento é novidade no ambiente da jurisdição, dado o aspecto público que a encerra, o que torna evidente que o poder de determinação das partes está limitado à sua esfera de disponibilidade e condicionado à verificação de capacidade das partes. Neste sentido, as normas que encerram evidente interesse público não estão ao alcance das partes, como as regras de competência absoluta, pressupostos processuais, além de, naturalmente, os princípios de ordem constitucional que resguardam o devido processo legal.

Ainda que a concretização do negócio processual requeira o acompanhamento e a chancela do magistrado que conduz o processo como expressão do princípio da cooperação processual $\left(\operatorname{art}^{\circ} 6^{\circ}\right)$, a remodelação do ritual de solução de conflitos de acordo com o interesse das partes constitui-se em significativa abertura para a autodeterminação das partes e para a harmonização entre o rito e o conflito, algo muito semelhante ao que ocorre no ambiente da arbitragem nos termos da Lei 9.307/1996. 36 Relatório Justiça em Números 2016, p.57. 
Como se observa, a legislação parece estar preparando um ambiente de solução de conflitos em que a cultura do diálogo pode ser capaz de recrudescer e impactar positivamente o acesso à justiça. $E$ todo ambiente de diálogo pressupõe abertura e cooperação, não sendo outro o escopo previsto no art. $6^{\circ}$ do novo CPC.

Outra evidência de que a jurisdição esteja se despindo de sua autoridade plena e atribuindo igual legitimidade a outros ambientes, nos quais a via do consenso seja suficiente para redefinição de relações jurídicas, é a gradativa delegação de demandas tipicamente judiciais aos cartórios extrajudiciais, ${ }^{37}$ a exemplo dos divórcios consensuais, partilhas amigáveis e mais recentemente o procedimento de usucapião, a partir da alteração da Lei de Registros Públicos pelo art.1071 do novo CPC.

Pelo que se observa, de um lado, há uma evolução de políticas públicas voltadas para uma nova perspectiva de solução de conflitos, que apostam sobretudo na participação e na cooperação dos sujeitos processuais. De outro, há que se verificar se os profissionais estão preparados para o ambiente do consenso.

Primeiramente, muito embora a audiência do art.334 já tenha rendido críticas contrárias ao novo procedimento, ${ }^{38} \mathrm{O}$ art.2 ${ }^{\circ}$, parágrafo único do novo Código de Ética da $O A B$, em seu inciso VII, há um clamor ético que se impõe sobre os adeptos e sobre os céticos, ou seja, é dever do advogado "estimular, a qualquer tempo, a conciliação e a mediação entre os litigantes, prevenindo, sempre que possível, a instauração de litígios". 39

É preciso compreender que, para a advocacia, há novas perspectivas de trabalho na prática do consenso. Além de atender aos aspectos éticos da profissão, que comprometem o advogado a evitar a judicialização dos conflitos, conduzir a solução do conflito pela via do consenso não só continua a remunerar o trabalho do profissional como traz mais eficácia aos serviços prestados em menor tempo e com desgaste reduzido ou até inexistente. Trata-se de uma questão de perspectiva e pragmatismo profissional.

37 THEODORO JR. Humberto. Curso de Direito Processual Civil. Vol.1. Rio de Janeiro: Forense: 2016, p.144.

38 MACHADO, Marcelo Pacheco. Como escapar da audiência de mediação e de conciliação do novo CPC. Disponível em: http://www.seac-abc.com.br/noticias/mostrar.php?codigo=18862. Acesso em: 21 mar. 2017.

39 ORDEM DOS ADVOGADOS DO BRASIL. Resolução 02/2015. Disponível em: <http://www.oab.org.br/arquivos/ resolucao-n-022015-ced-2030601765.pdf. Acesso em: 21 mar. 2017. 
Mas a resistência também se observa dentro do próprio Judiciário, em que alguns magistrados, por exemplo, justificam-se pela carência de mediadores e de conciliadores, ${ }^{40}$ muito embora a total falta de crença no consenso, nas veias do Judiciário, seja o maior desafio a ser suplantado. ${ }^{41}$

Mas a verdade é que tudo começa lá, naquele lugar chamado sociedade, na microfísica do poder. É nesta sociedade, não tão distante, em que estão as Faculdades de Direito, que muito recentemente têm incluído em seus "projetos pedagógicos" conteúdos relacionados ao consenso na solução de conflitos. Sim, uma mudança quase intempestiva, quase tardia para a vida contemporânea, que já deveria ter sobretudo incorporado o consenso na sua genética social. Mas que seja ao menos um começo de relevância na formação acadêmica, como uma aposta para o um presente muito próximo.

Da mesma forma, por mais tecnologia que se possa acessar, por mais recursos que se possam obter, por mais lógico e dialógico que seja a sistemática de tratamento dos conflitos, nenhuma política pública se sustenta sem a cooperação dos sujeitos processuais envolvidos neste processo. Trata-se de uma perspectiva cultural que pode ser revertida em favor do diálogo, pois segundo Oscar Chase, ${ }^{42}$

Os processos de resolução de litígios são, em grande medida, um reflexo da cultura em que estão inseridos; não se trata de um sistema autônomo que seja, predominantemente, o produto de especialistas e experts isolados. Mais, eles são instituições através das quais a vida social e cultural é mantida, provocada e alterada, ou como a mesma ideia foi expressa, constituída ou construída.

Nessa mesma linha, com razão Boaventura de Sousa Santos, ao defender que não basta mudar o direito substantivo e o direito processual, quando muitas outras mudanças devem ser implementadas, e estas passam pela necessidade de criação de uma outra cultura jurídica e judiciária, o que inclui uma nova formação de magistrados e de "outras faculdades de direito". ${ }^{43}$

40 Conselho Nacional de Justiça. Novo Código de Processo Civil rompe resistências de juízes à conciliação. Disponível em: < http://www.cnj.jus.br/noticias/cnj/84500-novo-codigo-de-processo-civil-rompe-resistencias-dejuizes-a-conciliacao-2. Acesso em: 23 mar. 2017.

41 FREITAS, Carmen Lúcia Kaltbach de. Festa ou Solenidade? Conciliação e Mediação como caminhos de acesso à justiça. Curitiba: Prismas 2016, p.142-143.

42 CHASE, Oscar G. Direito Cultura e Ritual: Sistemas de Resolução de conflitos no contexto da cultura comparada, p.21.

43 SANTOS, Boaventura de Sousa. Para uma revolução democrática da justiça. 3. ed. São Paulo: Cortez, 2011, p.38. 
A partir dessa perspectiva, fica evidente que o ambiente afeta e é afetado pelos processos de resolução de litígios, de modo que, se a proposta não brota naturalmente do seio da sociedade, será a sociedade o destino e o foco dessa mudança de perspectiva, dessa revolução necessária para a adaptação dos rituais aos conflitos.

No Brasil, por determinação constitucional, o Estado Democrático de Direito deve oportunizar ao cidadão, por meio de políticas públicas, o exercício pleno de sua cidadania através de mecanismos adequados que assegurem a proteção jurídica de seus direitos. A jurisdição, em definitivo, não é mecanismo único. Neste sentido, a via consensual, quando compatível com o conflito, não parece uma ideia a ser recepcionada, mas um dever ético a ser atendido.

Portanto, ainda que pareça paradoxal esperar o senso de comunidade em uma sociedade contemporânea caracterizada pela intolerância de toda ordem, o fato é que a sociedade deverá recepcionar essa nova lógica, bem como se renovar culturalmente, assumindo novos valores e crenças, apostando na via consensual como uma nova e efetiva racionalidade de solução de controvérsias.

\section{JUSTIÇA E CONSENSO: O ACESSO À JUSTIÇA SOB A PERSPECTIVA CULTURAL DO DIÁLOGO}

"...o diálogo com os outros, suas objeções ou sua aprovação, sua compreensão ou seus mal-entendidos, representam uma espécie de expansão de nossa individualidade e um experimento da possivel comunidade a que nos convida a razão". (Gadamer, Verdade e Método II, p.246)

Processos sem juiz? Audiências sem o tradicional layout das salas dos fóruns? Ambientes sem os tablados adversariais e sem sujeitos polarizados?

Muito bem. É preciso admitir que não se mostra simplória a tentativa de legitimar um espaço sem jurisdição, um ambiente sem juiz e sem a simbologia clássica das salas do Judiciário. Trata-se de uma representação de poder fortemente arraigada na cultura jurídica. Não bastasse isso, é comum a resistência da própria comunidade jurídica frente à ideia de procedimentos não adversariais, o que se justifica por uma 
cultura habituada a polarizar as relações e que, infantilizada e assujeitada, sempre se colocou à espera de uma decisão de um terceiro sobre a lide.

Oscar Chase defende a invocação à cultura como ferramenta para compreender os processos de resolução de conflitos é uma necessidade, pois as instituições de resolução de conflitos são ao mesmo tempo um produto, um colaborador e um aspecto da cultura, de modo que suas formas evidenciam qualidades inerentes a determinada sociedade. ${ }^{44}$

Nesse sentido, partindo da concepção de que a cultura expressa ideias, valores e crenças cognitivas e normativas, Chase argumenta que a relação entre cultura e resolução de conflitos é reflexiva, pois o processo auxilia na construção da cultura, ou influencia este fenômeno, bem como lhe serve de expressão. ${ }^{45}$

De tal sorte, o uso de mecanismos não adversariais de solução de conflitos possuem inversamente um efeito transformador da própria sociedade, pois na medida em que são aplicados, dada sua capacidade de revolucionar as relações, extraindo das partes as latências do conflito, acabam por aprimorar os laços sociais por meio do consenso. ${ }^{46}$

O resultado dessas intervenções, após internalizadas no seio social, seria capaz de criar valores de cooperação e solidariedade, que por si retroalimentariam a crença na sistemática consensual. Essa é uma perspectiva capaz de impactar as bases de uma sociedade complexa e individualista, ainda que a longo prazo.

Os procedimentos da mediação, da conciliação e da arbitragem são exemplos desse argumento. Para Chase, a mediação, devido à sua ênfase na resolução consensual da disputa, ganhou importância para aqueles que possuíam em elevada conta os valores do comunitarismo e da autodeterminação. Já a arbitragem é corriqueiramente encampada por interesses de mercado devido à sua potencial economia diante da jurisdição, à privacidade de que a decisão é cercada e à confiança no conhecimento específico de julgadores sobre a espécie de questão a ser decidida. ${ }^{47}$

44 CHASE, Oscar G. Direito Cultura e Ritual: Sistemas de Resolução de conflitos no contexto da cultura comparada, p.27.

45 CHASE, Oscar G. Direito Cultura e Ritual: Sistemas de Resolução de conflitos no contexto da cultura comparada, p.171.

46 CHASE, Oscar G. Direito Cultura e Ritual: Sistemas de Resolução de conflitos no contexto da cultura comparada, p.152 e 184.

47 CHASE, Oscar G. Direito Cultura e Ritual: Sistemas de Resolução de conflitos no contexto da cultura comparada, p.136. 
Sob outro aspecto, diferentemente do ritual contencioso, as técnicas que apostam no diálogo trabalham com a expectativa do que está latente às pretensões resistidas. No processo judicial, a pretensão é registrada em uma petição inicial que congela o tempo do conflito. ${ }^{48} \mathrm{~A}$ lide, portanto, torna-se anacrônica. Já no ambiente do diálogo, segundo Luis Alberto Warat, sempre existe um momento para introduzir o dado faltante ou corrigir o que já foi dito, na medida em que se reconhecem as armadilhas do inconsciente que o mediador está apto a desvendar. ${ }^{49}$

De acordo com Marcelo Brodsky, colocar em palavras "o não-dito produz um alívio considerável, permitindo que as partes exponham sobre o que realmente interessa: o conteúdo latente do conflito que os traz à mediação". ${ }^{50}$

Para Márcia Tiburi, "a falta de diálogo é o sintoma não apenas da ausência de reconhecimento, mas de uma projeção violenta de uma verdade sobre o outro". ${ }^{51}$ O meio adversarial, guardadas as devidas proporções, recria essa simbologia de beligerância.

Para Warat, a mediação é um trabalho simbólico sobre a administração e a reconstrução dos conflitos, na qual se destaca o valor da palavra, da comunicação, do diálogo, da escuta, da interpretação e da transferência. Para tanto, para "trabalhar sobre um conflito implica aceitar que para resolvê-lo não é preciso aniquilar o outro", na medida em que é possível encontrar uma solução que respeite a diferença do outro..$^{52}$ É o espaço de realização da alteridade..$^{53}$

Com essa mesma perspectiva, o consenso necessário para o negócio processual também é um impacto no rito processual, pois a simples abertura dada a discutir o rito já desfaz a beligerância desencadeada pelo processo contencioso. São muitas as possibilidades de ampliação do consenso a partir da abertura para o diálogo.

A solução advinda do consenso é plena, preventiva e justa. A justiça do consenso é a justiça das partes.

48 WARAT, Luis Alberto (Org.). Em nome do acordo. A mediação no direito. 2. ed. Buenos Aires: Almed, 1999, p.12-13.

49 WARAT, Luis Alberto (Org.). Em nome do acordo. A mediação no direito, p.12-13.

50 BRODSKY, Marcelo. Psicanálise e Mediação. In WARAT, Luis Alberto (Org.). Em nome do acordo. A mediação no direito. 2. ed. Buenos Aires: Almed, 1999, p.62.

51 TIBURI, Márcia. Como conversar com um fascista. São Paulo: Record, 2016, p.187.

52 WARAT, Luis Alberto (Org.). Em nome do acordo, p.36-37

53 WARAT, Luis Alberto (Org.). Em nome do acordo, p.40. 
Segundo Hans-Georg Gadamer, dentro da experiência hermenêutica, a percepção de mundo é ineludivelmente algo privado, assim como os impulsos e os interesses dão a cada um sua individualidade, responsável por ofuscar a razão que é capaz de apreender o que é comum a todos. É por isso que o diálogo é um convite à comunidade, ${ }^{54}$ pois "O que perfaz um diálogo não é termos experimentado algo de novo, mas termos encontrado no outro algo que ainda não havíamos encontrado em nossa própria experiência de mundo". ${ }^{55}$

Diante disso, o comportamento dado à abertura para a tradição é elemento integrante e é próprio da consciência histórica, que Gadamer vai chamar de experiência histórica efeitual. ${ }^{56}$ Assim, a consciência histórica, por Gadamer, é um saber da alteridade do outro e do passado em sua alteridade, do mesmo modo que a compreensão do tu sabe do mesmo como pessoa. ${ }^{57}$

Sob outro aspecto, se a linguagem constitui, é possível criar um cenário consensual a partir de políticas públicas de acesso à justiça voltadas para rituais que, pautados no diálogo, seja por meio da mediação, da conciliação e da restauração das relações, promovam efetivamente mudanças que, após internalizadas no meio social e jurídico, passem a ser utilizadas naturalmente ao lado da jurisdição.

Eis a importância de uma revisão do que é cultuado. Eis os argumentos para que os sujeitos processuais se abram para novas perspectivas, suspendendo seus preconceitos, pois é sempre bem-vindo o alerta de Gadamer, para quem "aqueles que não querem se conscientizar dos preconceitos que o dominam, acabam se enganando sobre o que se revela sob a luz". ${ }^{58}$

\section{CONSIDERAÇÕES FINAIS}

Com a proposta da justiça consensual, desencadeada pelo novo CPC, especialmente a partir da audiência de mediação ou de conciliação do novo rito comum, é possível esperar um ensaio de uma nova racionalidade processual, na qual o protagonismo das partes, em ritmo de cooperação, é capaz de tratar e transformar os conflitos a partir do diálogo.

\footnotetext{
54 GADAMER, Hans-Georg. Verdade e Método II. São Paulo: Vozes, 2002, p.246.

55 GADAMER, Hans-Georg. Verdade e Método II. p.247.

56 GADAMER, Hans-Georg. Verdade e Método I, 6. ed. São Paulo: Vozes, 2004, p.471.

57 GADAMER, Hans-Georg. Verdade e Método I, p.470.

58 GADAMER, Hans Georg. Verdade e Método I, p.471.
} 
Não se trata apenas de um caminho escolhido para tangenciar as estatísticas da litigiosidade, muito embora, como já dito anteriormente, em razão do acervo excessivo de litígios, há uma tendência de que a jurisdição venha despir-se de sua autoridade de maneira gradativa. Trata-se, sim, de uma lógica legítima e capaz de revolucionar a cultura jurídica, na medida em que os meios consensuais apresentam técnicas pragmáticas e eficazes de resolver os conflitos sociais. Portanto, os resultados são positivos não só para o cidadão como também para os profissionais imbricados nesse processo.

Sob o ponto de vista do cidadão, essa mudança de perspectiva é bem mais nobre, qual seja o da possibilidade de rever o conflito com o outro, ao considerála igualmente como cidadão implicado neste processo, restabelecendo o contato e, junto dele, transformar o conflito em algo melhor e justo para ambos, eis que a solução fora construída de mãos dadas. Trata-se de uma autocomposição com traços sobretudo personalíssimos, resultante da decisão recíproca daqueles que efetivamente experimentaram o conflito.

Isso ganha ainda mais notoriedade diante dos conflitos de família e também de vizinhança, cuja excentricidade e seus vínculos de convivência antes, durante e depois do conflito ocupam um espaço significativo nos fóruns de todo o país.

Sob o ponto de vista profissional, sobretudo da advocacia, a mediação, a conciliação, a arbitragem e o negócio processual, a partir da abertura para o consenso, denotam a sensibilidade do profissional na busca pela compatibilidade entre a natureza dos conflitos e os rituais adequados para o seu tratamento. Isso significa atribuir pragmaticidade, celeridade e eficácia na promoção do acesso à justiça.

Para tanto, é importante partir do pressuposto de que a jurisdição, na qual o juiz se substitui às partes para submetê-las à sua decisão (heterocomposição), nem sempre será a via mais adequada para a solução de todo e qualquer conflito ${ }^{59}$, e que, além disso, a própria jurisdição precisa rever seus rituais e oferecer uma lógica processual menos adversarial e mais dialógica, provocando e instigando a cooperação e a participação efetiva das partes conflitantes na busca do rito e da solução adequada no caso concreto.

59 ALMEIDA, Rafael Alves de; ALMEIDA, Tania; CRESPO, Maria Hernandez (Org.). O Tribunal Multiportas Investindo no capital social para maximizar o sistema de solução de conflitos no Brasil. Rio de Janeiro, Editora FGV, 2012. Disponível em: http://bibliotecadigital.fgv.br/ dspace/bitstream/handle/10438/10361/Tribunal\%20 Multiportas.pdf?sequence=1. Acesso em: 20 mar. 2017. 
Não é digno o cidadão ser submetido a um procedimento que não seja adequado à natureza do seu conflito. Da mesma forma, conflitos desiguais em sua natureza, produtores de pretensões especiais, não podem ser tratados ou conduzidos por meio do mesmo rito comum. Por isso, os rituais de solução de conflito somente podem ser constitucionalmente adequados quando não criarem obstáculos de acesso à justiça, ao tempo em que promovam a dignidade do cidadão e respeitem a sua cidadania.

É preciso, portanto, um despertar sobre o uso dos procedimentos disponibilizados pelo ordenamentojurídico, sobre sua adequação frente à natureza de cada conflito e em especial sobre o compromisso de tais procedimentos frente aos valores constitucionais que permeiam o acesso à justiça. Para tanto, com insistência, é preciso olhar para o conflito, cientes de que o "diálogo não é uma salvação, mas um experimento ao qual vale a pena somar esforços se o projeto político for coletivo". 60

Se o consenso parece ser incompatível com uma sociedade complexa e individualista, que os rituais consensuais façam o seu papel de (re)orientação e sejam internalizados em nossa cultura jurídica, transformando as relações sociais e reforçando o próprio consenso. O consenso é cativante, pois a justiça do consenso é plena, preventiva e justa. A justiça do consenso é a justiça das partes. Para esse novo olhar, estão todos convidados.

\section{REFERÊNCIAS DAS FONTES CITADAS}

ALMEIDA, Rafael Alves de; ALMEIDA, Tania; CRESPO, Maria Hernandez (Org.). O Tribunal Multiportas - Investindo no capital social para maximizar o sistema de solução de conflitos no Brasil. Rio de Janeiro: Editora FGV, 2012. Disponível em: http://bibliotecadigital.fgv.br/ dspace/bitstream/handle/ 10438/10361/Tribunal\%20Multiportas.pdf?sequence=1. Acesso em: 20 mar. 2017.

BOLZAN DE MORAIS, José Luis. O Estado e seus limites. Reflexões iniciais sobre a profanação do Estado Social e a dessacralização da modernidade. Boletim da Faculdade de Direito n. 83, 2007. p.576-577

BOURDIEU, Pierre. O poder simbólico. Tradução de Fernando Tomaz. Rio de Janeiro: Bertrand Brasil, 2006.

60 TIBURI, Márcia. Como conversar com um fascista. São Paulo: Record, 2016, p.32. 
BRASIL.ORDEM DOS ADVOGADOS DO BRASIL. Resolução 02/2015. Aprova o Código de Ética e Disciplina da Ordem dos Advogados do Brasil - OAB. Disponível em: <http://www.oab. org.br/arquivos/resolucao-n-022015-ced-2030601765.pdf. Acesso em: 21 mar. 2017.

BRASIL, Conselho Nacional de Justiça. Relatório Justiça em Números 2016. Volume 1. Disponível em: http://www.cnj.jus.br/files/conteudo/arquivo/2016/ 10/b8f46be3dbbff34493 1a933579915488.pdf. Acesso em: fev. 2017.

BRODSKY, Marcelo. Psicanálise e Mediação. In WARAT, Luis Alberto (ORG.). Em nome do acordo. A mediação no direito. 2. ed. Buenos Aires: Almed, 1999.

CALMON, Petrônio. Fundamentos da mediação e da conciliação. 3. ed. Brasília: Gazeta Jurídica, 2015.

CAPPELletTI, Mauro; GARTH, Bryant. Acesso à Justiça. Tradução de Ellen Gracie. Porto Alegre: Fabris, 1988.

CHASE, Oscar G. Direito Cultura e Ritual: Sistemas de Resolução de conflitos no contexto da cultura comparada. 1. ed. Tradução de Sérgio Arenhart, Gustavo Osna. São Paulo: 2014.

CHIOVEDA, Giuseppe. Instituições de direito processual civil. Tradução Paolo Capitaneo. Campinas: Bookseller, 1998, Vol.2.

FREITAS, Carmen Lúcia Kaltbach de. Festa ou Solenidade? Conciliação e Mediação como caminhos de acesso à justiça. Curitiba: Prismas 2016.

GADAMER, Hans Georg. O problema da consciência histórica. Tradução de Paulo César Duque Estrada. Rio de Janeiro: Fundação Getúlio Vargas, 2003.

GARAPON, Antoine. O guardador de promessas: justiça e democracia. Tradução de Francisco Aragão. Lisboa: Instituto Piaget, 1996.

FOUCAULT, Michel. Microfísica do poder. 26. ed. Tradução de Roberto Machado. Rio de Janeiro: Graal, 1979.

LACAN, Jacques. Os complexos familiares na formação do indivíduo. Tradução de Marco Antônio Coutinho Jorge e Potiguara Mendes da Silveira Júnior. Rio de Janeiro: Jorge Zahar, 2002.

LIPOVETSKI, Gilles. A era do vazio: ensaios sobre o individualismo contemporâneo. Tradução de Therezinha Monteiro Deutsch São Paulo: Manole, 2005.

MARINONI, Luiz Guilherme. Teoria Geral do Processo. 7. ed. São Paulo: Revista dos Tribunais, 2013. MAUS, Ingeborg. O Judiciário como superego da sociedade: o papel da atividade jurisprudencial na "sociedade órfã". Novos Estudos CEBRAP, São Paulo, n. 58, p. 183-202, nov. 2000. Disponível em: http://www.direitocontemporaneo.com/wp-content/uploads/2014/02/ 
JUDICI\% C3\%81RIO-COMO-SUPEREGO-DA-SOCIEDADE.pdf. Acesso em: 01 jun. 2017.

MEDINA, José Miguel Garcia. Direito Processual Civil Moderno. 2. ed. São Paulo: Revista dos Tribunais, 2016.

NERY JR., Nelson. Comentários ao Código de Processo Civil. São Paulo: RT, 2016.

SILVA, Ovídio Baptista da. Processo e Ideologia - o paradigma racionalista, 2. ed. Rio de Janeiro: Forense, 2006.

SANTOS, Boaventura de Sousa. Para uma revolução democrática da justiça. São Paulo: Cortez, 2011.

SANTOS, Karinne Emanoela Goettems dos. Processo Civil e Litigiosidade - Para além da jurisdição dos conceitos sem coisas. Rio de Janeiro: Lumen Juris, 2016.

THEODORO JR., Humberto. Curso de Direito Processual Civil. Vol 1. Rio de Janeiro: Forense, 2016. TIBURI, Márcia. Como conversar com um fascista. São Paulo: Record, 2016.

WARAT, Luis Alberto (Org.). Em nome do acordo. A mediação no direito. 2. ed. Buenos Aires: Almed, 1999.

Recebido em: junho/2017

Aprovado em: fevereiro/2018 